\title{
Obesidad y sobrepeso en creencias y actitudes de pobladores de una comunidad urbana desde la Sociología de la Salud
}

\author{
Eudosio H. Sifuentes León \\ Universidad Nacional Mayor de San Marcos \\ esifuentes/@unmsm.edu.pe \\ Luisa H. Rivas Díaz \\ Universidad Nacional Mayor de San Marcos \\ Irivasd@unmsm.edu.pe
}

\begin{abstract}
RESUMEN
Obesidad y sobrepeso son problemas de malnutrición y de salud pública en las comunidades y sociedades de la época actual. Detener y reducirlos son objetivos inmediatos del desarrollo, que no todos asumen, especialmente los afectados por su comportamiento y mentalidad, que amerita conocerlos. El estudio explora las creencias y actitudes de pobladores de una comunidad urbana, frente a la obesidad y el sobrepeso, aplicando un enfoque mixto, cualitativo observacional en su primera parte y cuantitativo, descriptivo, probabilístico por conglomerados, en la segunda. Fueron encuestados 240 pobladores, hombres y mujeres de 18 a 70 ańos; y fueron observadas 2456 personas de todas edades. El análisis triangula la información recogida mediante encuestas, entrevistas y observaciones. Se encontraron experiencias colectivas e individuales muy singulares en los procesos de socialización, alimentación y movilidad social; oportunidades para incorporar elementos de culturas locales, modernas y tradicionales; acceso a medios masivos y tecnologías de información con posibilidades de asimilar pautas de comportamiento, de consumo, de gustos y de prácticas de la sociedad global. Algunos pobladores, con kilos de más no les preocupaba su peso; otros, parecían alegres por tener hijos «gorditos», que los consideraban «normales», con «buena salud» y sobre todo por parecerse o tener «la pinta de limeños» y no de provincianos, mucho menos de «serranos»; lo que al parecer les permitía verse, en la jerarquía local, con más status y en un estrato más alto al de sus vecinos.
\end{abstract}

Palabras Clave: Sociología de la salud; creencias y actitudes; sobrepeso y obesidad, comunidades urbanas

\section{Obesity and overweight in beliefs and attitudes of residents an urban Community from the Sociology of Health}

\begin{abstract}
Obesity and overweight are problems of malnutrition and public health in the communities and societies of the current era. Stopping and reducing them are immediate objectives of development, which not everyone assumes, especially those affected by their behavior and mentality, which deserves to be known. The study explores the beliefs and attitudes of residents of an urban community, against obesity and overweight, applying a mixed approach, qualitative observational in the first part and quantitative, descriptive, probabilistic by conglomerates, in the second. 240 inhabitants were surveyed, men and women from 18 to 70 years old; and 2456 people of all ages were observed. The analysis triangulates the information collected through surveys, interviews and observations. Individual and collective experiences were very unique in the processes of socialization, nutrition and social mobility; opportunities to incorporate elements of local, modern and traditional cultures; access to mass media and information technologies with possibilities of assimilating patterns of behavior, consumption, tastes and practices of the global society. Some residents, with extra kilos did not worry about their weight; others, seemed happy to have "chubby» children, who considered them «normal», with "good health» and above all to look like or have «the look of Limeños» and not of provincials, much less of «serranos»; what apparently allowed them to see themselves, in the local hierarchy, with more status and in a higher stratum than their neighbors.
\end{abstract}

KeYworDs: Sociology of health; beliefs and attitudes; overweight and obesity; urban communities 


\section{El problema}

L a creciente prevalencia de obesidad y sobrepeso es un problema que afecta la salud pública en el ámbito nacional y global especialmente por sus consecuencias e impacto en el aumento de las probabilidades y riesgos de las enfermedades degenerativas, cardiovasculares, cancerígenas, diabetes y otras que afectan la vida de personas y colectividades. Por su magnitud se trata de un problema social que afecta a más de la tercera parte de la población nacional que siguen ciertos patrones y hábitos alimentarios bajo influencias culturales de un contexto de alto consumo y de estilos de vida no saludables.

La gordura, es un problema que se expresa en la acumulación desbordante de grasa en el organismo, a un nivel no saludable; que puede medirse con el Índice de Masa Corporal (IMC), formulado por el sociólogo belga Adolfo Quetelet en su propósito sociológico, por determinar el «hombre medio», como patrón de comparación y medida. En la actualidad el IMC es utilizado por las ciencias de la salud y de la nutrición. Este índice, se obtiene midiendo el peso de una persona en kilogramos, entre el cuadrado de la talla medido en metros. Si el resultado de esta operación va de 25 a 29 se considera sobrepeso; si es 30 o más, obesidad.

El peso excesivo de personas gordas o muy gordas es un factor que eleva el riesgo de contraer enfermedades crónicas, degenerativas y cancerígenas las cuales están en pleno crecimiento en la época actual; lo cual se complica por tener un tratamiento prolongado y costoso, inaccesible para quienes pasan por una situación de pobreza, sin seguro y con limitado acceso a los servicios de salud. La cadena de dolencias tiene efectos negativos en la economía familiar y en el trabajo, al mismo tiempo elevan los gastos del presupuesto nacional y de los programas de salud. Por consiguiente, el creciente número de gordos y muy gordos más que un tema de estética es una experiencia de malestar individual y familiar; pero también es un problema social, por lo que el estudio de sus características y de sus efectos compromete a la salud pública, a las políticas sociales, a la cultura y a los estilos de vida, desbordando los ámbitos de la biología o de la medicina curativa.

Desde la perspectiva sociológica se enfoca el crecimiento de la prevalencia de gente obesa y con sobre- peso como un hecho social, de dimensión mundial y local generado por una gama de fuerzas sociales, que afectan de manera creciente la vida de la población. Las situaciones de prevalencia del sobrepeso, asociado a las enfermedades crónicas, degenerativas y cancerígenas arrancaron por los países más desarrollados; pero ya llegaron a nuestras tierras, incubándose silenciosamente no solo en las grandes ciudades; sino también en las pequeñas; en las zonas olvidadas, incluso entre las poblaciones más pobres y excluidas del país. Su crecimiento ha sido tan acelerado que ha sorprendido en las estadísticas del nuevo milenio, llamando la atención de epidemiólogos y salubristas, que han puesto correctamente su mirada en los productos industriales que come la gente y en los hábitos cotidianos de alimentación.

La Organización Mundial de la Salud sostiene que la obesidad alcanzó, desde la década pasada, proporciones epidémicas en el mundo, estimando la existencia de 671 millones de obesos; concentrándose la mitad de éstos en 10 países altamente desarrollados (OMS, 2010). Mientras que con sobrepeso se han identificado a más de 1900 millones de personas. Entre los países con más obesos destacan en primer lugar China, luego Estados Unidos, Brasil, México, India. Los países anglosajones tienen los porcentajes más altos de obesidad, con relación a sus respectivas poblaciones como Estados Unidos, Inglaterra y Canadá; entre los latinoamericanos, México, 32\%; Venezuela, 30\%; Argentina, 29.4\%; Chile, 29.1\%; Uruguay, 23.5\% y Perú, 21\% (OMS, 2015).

En el Perú, la prevalencia de gordos y muy gordos se observa como un fenómeno más urbano que rural, atraviesa a todas las regiones, con predominio de la costa central. Poco más de la tercera parte de la población nacional, $35.5 \%$ tiene sobrepeso y $18.3 \%$, obesidad (ENDES 2017). Es decir, más de la mitad de los peruanos son gordos o muy gordos. En la población urbana, el sobrepeso afecta al $38.6 \%$, y la obesidad al $22.4 \%$; en la rural sorprende un $29.7 \%$ con sobrepeso; y $10.8 \%$ con obesidad.

Entre las ciudades con más sobrepeso destaca Lima e Ica en ambos casos con más del $42 \%$ de su población; mientras Huancavelica aparece con menos sobrepeso, $(25.5 \%)$ y obesidad (6.7\%). Las regiones con mayor porcentaje poblacional en obesidad son Ica con $29,4 \%$ y Tacna con $29.1 \%$, ambas superan a Lima, que sólo llega a 24.1\% (ENDES, 
2017). Considerando las diferencias económicas se observa que los ricos tienen más gordos (41.5\%) que los pobres $(26.2 \%)$.

El sobrepeso y la obesidad ahondan la situación de malnutrición en todas las regiones del país. Según ENDES 2016, los niños menores de 05 años del Perú se vieron afectados por la desnutrición crónica en un 13.1\%, solo en Huancavelica llegó al 33.4\%; mientras que en Tacna se estimó en $2.3 \%$ y en Lima $4.9 \%$. La prevalencia de anemia en niños de 3 a 6 años en el 2016 a nivel nacional fue de 43.6\%; en Puno ascendió a 75.9\%; mientras que en Lima estuvo alrededor del $40.9 \%$. En suma, las poblaciones con mayor pobreza y pobreza crónica están más afectadas por la desnutrición crónica y la anemia y en los últimos ańos se suma una prevalencia creciente de obesidad y sobrepeso.

El problema que encontramos como objetivo de investigación, es que mientras los profesionales de la salud, del MINSA y de los organismos multilaterales del mundo y del continente vienen dando la voz de alarma sobre el rápido aumento de sobrepeso y obesidad, subrayando que se trata de una epidemia, que eleva las probabilidades de contraer diabetes, enfermedades cardiovasculares y cancerígenas; es decir, mientras en la esfera pública de los medios, organismos del Estado y de la política hay preocupación por la articulación y el impacto de tales enfermedades; entre los individuos y las familias hay actitudes opuestas; no solo viven con tranquilidad, sino con cierta satisfacción y complacencia, considerando, como se observa en algunos pobladores de San Gabriel Alto, un motivo de orgullo, creyendo expresar con la gordura un ascenso de status, al exhibir en el propio cuerpo, o de sus hijos y demás familiares, una imagen opuesta a la pobreza, al hambre o al consumo deficiente de alimentos.

En suma, se observa un desencuentro entre las explicaciones que proporcionan los expertos en salud y los organismos especializados por un lado y por otro las creencias, comportamientos y actitudes de la población que derivan en pautas de vida favorables a estos males o que podrían estar actuando como ideas fuerza, como mandato social induciendo a la gente a la malnutrición y a estilos de vida no saludables.

El problema planteado, de este modo, se orienta a conocer por qué los pobladores teniendo informa- ción de los riesgos y de las probabilidades de contraer enfermedades graves a partir del sobrepeso y la obesidad, asumen actitudes negativas hacia su prevención. Habiendo observado en ellos "complacencia», creyendo que tales males no son de riesgo para la salud a pesar de la información que disponían; hecho que planteaba la importancia de explorar más a fondo el asunto, en el plano de la cultura, de las imágenes, de los sueños escondidos, considerando el contexto social y las múltiples relaciones interindividuales y sociales que demarcaban los estilos de vivir.

Por tal motivo, en la presente investigación se analizan principalmente las influencias culturales teniendo como referencia las creencias y actitudes identificadas con relación a la obesidad y el sobrepeso en los pobladores que habitan las zonas más altas de una comunidad urbana en situación de pobreza y exclusión llamada San Gabriel Alto del distrito de Villa María del Triunfo en la ciudad de Lima.

\section{Formulando el siguiente problema de investigación}

¿Cuáles son las creencias y actitudes de los pobladores de una comunidad urbana hacia la obesidad y sobrepeso años 2013-2016? Fue el problema central del estudio y considerados como elementos complementarios se plantearon las siguientes interrogantes:

¿Qué simboliza la gordura entre los hombres y entre las mujeres en un contexto de pobreza y de exclusión?

¿Qué actitud asumen los pobladores y cómo explican la gordura que tienen ellos y sus hijos en la comunidad?

¿Qué actitudes tienen los pobladores hacia la alimentación cotidiana?

\section{Metodología}

El estudio se realizó en las poblaciones de los asentamientos humanos de las zonas altas de San Gabriel Alto, del distrito de Villa María del Triunfo en Lima Metropolitana, que se formaron mediante invasiones masivas y con ocupación progresiva entre 1990 y el 2010, entre las cuales destacan: Cerro Verde, "14 de Enero», "Antonio Raimondi», La Florida, 
Andenes, Tiwinza, Virgen de Guadalupe, Nueva Jerusalem, Ampliación 25 de Diciembre, Vista Alegre, Ampliación Los Sauces, Las Casuarinas, Villa Sta. Rosa, Comité 47, Comité 39, Comité 23, Nueva Generación, Manuel Arévalo, Valle Hermoso y Las Rocas.

Se realizó un estudio de tipo mixto: cualitativo en la primera parte, a base de entrevistas en profundidad y a un trabajo de observación realizado entre el 2013 y el 2016. Cuantitativo en la segunda parte, con la aplicación de una encuesta a 240 pobladores, hombres y mujeres de 18 a 70 ańos de un universo poblacional aproximado de 16202 habitantes (Centro de Salud San Gabriel Alto 2014).

Se aplicaron guías de observación a las personas en dos planos distintos. La primera, para espacios públicos: parque de diversión y zona comercial; y la segunda, en espacios vecinales y domiciliarios.

Con la primera, se logró estimar en cada espacio público porcentajes aproximativos de personas, sean hombres o mujeres, niños, jóvenes o ancianos con rasgos claros de obesidad y sobrepeso. Se observaron los espacios públicos durante todo el día en cuatro tramos de 40 a 45 minutos en los siguientes horarios: de 08:00 a 09:00 horas, el segundo, de 12:00 a 13:00 horas; el tercero, de 17 a 18 horas; y el cuarto, de 19:00 a 20:00 horas en dos o tres días por semana, en el Parque 14 de enero y en la Av. José Carlos Mariátegui alrededor de las cuadras 20-28. Estas observaciones se realizaron durante 12 días entre setiembre y noviembre del 2016 logrando contabilizar a 2500 personas, que pasaban por cada uno de los espacios seleccionados. Una parte del equipo de trabajo contaba a todos los transeúntes y la otra solo a las personas que presentaban signos indiscutibles de sobrepeso y obesidad. Se trataba de una evaluación rápida, teniendo como resultado que la gran mayoría de las personas observadas con obesidad y sobrepeso eran mujeres; con una talla aproximada de $1.50 \mathrm{a}$ 1.60 metros, con un peso estimado de 75 a más y con más de un metro de cintura; además, el número de mujeres más altas de la talla mencionada era inferior al de las más bajas.

La presencia más baja de obesos, o muy gordos, fluctuaba aproximadamente entre $8.7 \%$ y $9.52 \%$ de la población transeúnte observada, en diferentes días especialmente de ocho a nueve horas por la mañana y entre las 20:00 y 21:00 hora, por la noche. En la zona comercial en diferentes días y horas se calculaba una presencia aproximada de $10.52 \%$ a $12.30 \%$ del total de caminantes. En cambio, en el parque había una presencia aparentemente mayor de $18.18 \%$ a $19.23 \%$ en las mañanas y en las tardes.

En la zona comercial se observaron personas que caminaban hacia el mercado, al centro de salud, a bodegas, restaurantes, talleres y viviendas. En la zona de recreación las personas se detenían por más tiempo, algunas se sentaban y los niños jugaban.

La guía de observación para espacios vecinales, compartidos por familias de dos o más viviendas incluía las miradas, los gestos y los dichos entre los padres y los vecinos; y de éstos hacia los niños con menos de 8 ańos, gordos y muy gordos; además de las condiciones físicas de la vivienda, la calidad y estado de la ropa de los niños y otros aspectos exteriores.

El riesgo en esta actividad es que el observador podía hacer prevalecer sus prejuicios o interpretaciones al calcular la dimensión de la contextura de los cuerpos, el significado de los comportamientos, o la expresión de frases y miradas entre los vecinos; sin embargo, el resultado de las estimaciones cuantificables concordaba con las estadísticas del sector y con la opinión de algunos dirigentes vecinales.

\section{El enfoque desde la Sociología de la Salud}

La Sociología de la Salud, enfoca la salud humana como un estado relativamente continuo de bienestar y de fuerza, de gozo y de vida plena, que experimentan individuos, grupos y poblaciones con plena interacción y cohesión orgánica en contextos saludables y de buen vivir. La salud se observa como un hecho social, determinado por fuerzas o «determinantes» sociales tales como la sociedad, la cultura, las clases sociales, los estilos de vida; que a su vez tienen efectos e impactos en la vida individual y colectiva. Desde el enfoque del desarrollo humano se considera la salud como el eje fundamental en la vida del ser humano y de la sociedad y tiene como finalidad el desarrollo social. Desde esta perspectiva, la Sociología de la Salud analiza los elementos característicos de la cultura como son las creencias y actitudes relacionadas al sobrepeso y a la obesidad y al impacto e influencia en la vida de las personas de poblaciones específicas y en el bienestar general de la sociedad. En este sentido, 
el estudio también se encuadra en los objetivos de la Salud Pública.

Durante el proceso formativo de la sociología (1820-1920); el estudio de las epidemias, de las enfermedades transmisibles y contagiosas que afectaban a poblaciones enteras, estuvieron en manos de médicos y científicos que encontraron al factor social como fundamental al abordar la identificación de los determinantes causales, así como también en las alternativas y posibilidades de control y eliminación de las dolencias y cuidado de la salud colectiva; es así como incursionaron en la medicina social o en la Sociología sin ser sociólogos; considerándolo hasta el presente como un factor importante en el estudio y control de enfermedades transmisibles y no transmisibles en el Perú y en algunas regiones de América, evidenciándose, en las últimas décadas, no solo en las estrategias establecidas por el sector salud, sino también en la consideración de los determinantes de salud y el los objetivos de desarrollo del Milenio.

En la actualidad, el foco principal de atención de los sociólogos de la salud son las epidemias del siglo XXI y las enfermedades crónicas, degenerativas y cancerígenas, sin descuidar el estudio de la situación de salud de las poblaciones agobiadas por los efectos de las enfermedades contagiosas. En este sentido, las creencias y actitudes acerca del sobrepeso y la obesidad se articulan a las percepciones colectivas con relación a las nuevas enfermedades de la sociedad moderna. Además, su campo de observación ya no está solo en el mundo rural, sino prioritariamente en las comunidades urbanas, tanto de las pequeñas y medianas, como de las grandes ciudades. En buena cuenta, su razonamiento y perspectivas se han puesto a la orden del día en la sociedad actual y a diferencia del pasado, es asumido directamente por los sociólogos a través de mecanismos interinstitucionales e interdisciplinarios.

\section{Resultados}

Los pobladores jóvenes de las comunidades urbanas comprendidas en el estudio, en su gran mayoría, son nacidos en Lima; pero con experiencias de vida en comunidades rurales y en las comunidades urbanas cercanas, donde pasaron por procesos de socialización, de aprendizaje de pautas culturales provenien- tes del ámbito global, pero también de las comunidades urbanas y rurales de donde provienen sus padres, abuelos y bisabuelos.

Se logró determinar el ámbito del estudio ubicado en los asentamientos concentrados entre la IV y V Etapa de San Gabriel Alto del distrito de Villa María del Triunfo que ocupa un espacio con una topografía de cerros pedregosos, de fuerte pendiente, que fueron ocupados de manera informal por miles de pobladores migrantes o limeños de otras zonas del mismo distrito o de distritos vecinos; la distribución y construcción de sus viviendas posibilita, en cada piso o anden que los vecinos se vean, se reconozcan y tramen amistad e intercambios de hábitos alimentarios y sanitarios, de ideas y experiencias de vida, posibilitando niveles de cohesión ante los retos comunes de sobrevivencia.

En esas condiciones espaciales y sociales, se logró identificar algunas creencias acerca del sobrepeso y la obesidad, de las causas que generan estos problemas, de sus manifestaciones y efectos en la salud de las personas. También se pudo identificar las percepciones de los pobladores acerca de la imagen de belleza y salud, con relación al sobrepeso y la obesidad. Preguntando cómo se ven, cómo se autoevalúan; cómo se sienten; si aceptan tener o estar con sobrepeso o no; si son obesos o no. Sus respuestas permitieron contrastar con los resultados de la observación, encontrando numerosas personas con declaraciones discordantes con su imagen real. Eran obesas; pero se declaraban «normales» o tener un "peso normal» y lo más importante en este desencuentro, es que decían estar satisfechas con su peso.

Aproximadamente tres cuartas partes de la población estudiada nacieron en Lima; el $58.4 \%$ de los encuestados de 18 a 70 años así lo confirmaron (Encuesta propia: 2017, Cuadro 3). Sin embargo, la mayoría $65.7 \%$ tenía sus raíces familiares en las comunidades rurales y en las pequeńas localidades de las regiones de Apurímac, Ayacucho, Huancavelica, Huánuco y Puno. El 41.7\% tenía educación secundaria completa; el 37.5\% educación superior; solo el 20.8\% primaria (Encuesta propia: 2017 Cuadro 3 ); ninguno se declaró analfabeto, aunque entre los que se negaron a responder probablemente hubo uno o dos analfabetos, ya que personal del MINSA había estimado en la zona la existencia de un $4 \%$ de analfabetos. 
En cuanto a la talla, el $64.2 \%$ declaró que su estatura estaba entre 1.51 y $1.60 \mathrm{~m}$; el $31.2 \%$ de 1.61 a 1.70; el 4.6\% declaró tener una estatura por debajo de $1.50 \mathrm{~m}$ (Encuesta propia: 2017, Cuadro 3 ). En cuanto al peso, el $33.3 \%$ declaró que estaba entre 51 y 60 kilos; $41.7 \%$ entre 61 y 70 Kilos y un $25 \%$ no sabía su peso (Encuesta propia 2017, Cuadro 3). En el proceso de aplicación de la encuesta, el encuestador y el encuestado hicieron el ejercicio de determinar el IMC del encuestado llegando a la conclusión de que el $47.5 \%$ tenía una IMC de 25 a 30 es decir de sobrepeso; y el $8.3 \%$ con más de 30 en el campo de la obesidad (Encuesta propia 2017, Cuadro 3).

Llegando a la conclusión de que el $16.7 \%$ eran altos y gruesos, de robustos a obesos; pero el $37.5 \%$ eran chatos y gruesos, de robustos a obesos. El 54.4\% de los entrevistados fueron vistos como chatos o altos, pero gruesos, robustos, gordos y obesos. (Encuesta propia: 2017 Cuadro 3)

El $12.5 \%$ eran altos y flacos probablemente por influencia genética y sobre todo por la buena nutrición y los estilos de vida saludables; mientras que los chatos y flacos llegaban al $16.7 \%$, este sería el grupo de los que en su infancia habrían pasado por períodos de desnutrición crónica; finalmente había otro $16.7 \%$ de medianos entre flacos y robustos. (Encuesta propia 2017, Cuadro 3).

En cuanto a las percepciones acerca de la belleza física: para el 58.3\% respondió que las personas bonitas tienen una "contextura normal»; el 16.7\% dijo "cualquier contextura», es decir que la bonita podía ser flaca o gorda, era lo secundario; sin embargo, el $8.3 \%$ dijeron que eran los "gordos» y otro $16.7 \%$ apuntaba por los flacos. (Encuesta propia: 2017, Cuadro 4) A la pregunta por la contextura del niño bonito, 54.2\% apuntó por el «normal». El 25.0\% declaró que el niño bonito era "flaco» mientras que para el 12\% era el "gordo" (Encuesta propia 2017, Cuadro 4); pero según las entrevistas muchos consideraban «normal» al niño robusto, con sobrepeso.

¿Quiénes podían ser más felices? El 33.3\% precisó por el niño «normal» y el $37.5 \%$ por "cualquiera», gordo o flaco; sumando ambos criterios se trataba de la opinión mayoritaria, $70.8 \%$; el resto opinó que cuando se es gordito (Encuesta propia 2017, Cuadro 5).

Asociando la contextura de las personas con la situación socioeconómica, la mayoría 33.3\% consideró que los «ricos» son «gordos»; lo cual concuer- da con el imaginario popular que define la gordura como una señal de riqueza. Para el $25 \%$ era «normal» y para otro $25 \%$ era "cualquiera»; sólo para el 16.7\% eran los flacos (Encuesta propia 2017, Cuadro 6).

Continuando con las indagaciones acerca de la relación entre contextura y clase social. El 41.7\% cree que los pobres son «flacos»; para el 29.2\% el pobre tiene una contextura normal y para el $25 \%$ puede ser "cualquiera». $4.2 \%$ sostuvo que con mayor frecuencia los pobres eran «gordos» por descuido, por comer lo que hay, o lo que llena el estómago con mayor facilidad (Encuesta propia 2017, Cuadro 6).

En la relación contextura-enfermedad; para el $62.5 \%$ el enfermo puede tener cualquier contextura; esto es irrelevante, porque todos pueden enfermarse, el 20.8\% cree que los gordos son más propensos a enfermarse; pero para el $16.7 \%$ son los flacos (Encuesta propia 2017, Cuadro 7).

Respecto a la imagen que tienen de sí mismos, o de su propia identidad: $83.3 \%$ se veían como «normales»; o como "cualquiera» de las personas de la comunidad o de la ciudad de Lima. Solo $12.5 \%$ se consideraban "gordos»; y un $4.2 \%$ restante se veían como flacos aun estando con una contextura entre normal y sobrepeso (Encuesta propia 2017).

$\mathrm{Al}$ responder cómo se veían a sí mismos, no siempre coincidían con la realidad; ya que frecuentemente se veían como «normales» estando con sobrepeso o con déficit $(83 \%)$ por lo que se sentían «contentos con su contextura"; mientras que el $12.5 \%$ estaba descontento y en duda el $4.5 \%$ (Encuesta propia 2017, Cuadro 8).

Las respuestas con relación a los factores que generan, o influyen en la "gordura», se reagruparon y codificaron en cinco tipos o categorías de respuesta: Para el $51.7 \%$ el factor generador de gordura, estaba en la «mala alimentación, o alimentación no nutritiva" y en "comer mucho»; el 21.8\% atribuía a la «falta de ejercicios, asociado a la mala alimentación»; "Comer comida chatarra, grasas, frituras y harinas»; el $13.5 \%$ en "no trabajar, tener vida sedentaria», otro grupo, 13.0\%; "por haber tenido enfermedades y por falta de higiene» (Encuesta propia 2017, Cuadro 9).

Un porcentaje importante (más de la mitad de los encuestados) creen que hay una fuerte relación entre las enfermedades, el sobrepeso y la obesidad. El $37.5 \%$ respondió que «Ser gordo no es señal de buena salud»; «es señal de enfermedad; "que puede tener 
diabetes o enfermedades cardiovasculares»; el 25.0\% dijo que estar gordo o muy gordo, no es bueno; se trata de» mala salud. Es obesidad o sobrepeso». El $20.8 \%$ dijo que «perjudica la salud; impide realizar las actividades con facilidad»; sin embargo, contrariamente el $16.7 \%$ sostuvo que estar gordo o muy gordo «Es seńal de estar bien alimentado» (Encuesta propia 2017).

Respecto a las creencias de los pobladores acerca de los factores que elevan el peso y la gordura, se encontró que el $41.7 \%$ consideró como alimentos preferidos de los gordos y muy gordos: «Solo frituras, comida chatarra, grasas, comida grasosa«; el 29.2\%, «harinas, levaduras, comida chatarra, frituras y grasas»; el $16.7 \%$ creía que eran «dulces, golosinas, harinas, pastas, frituras y comidas grasosas»; mientras que el $12.5 \%$ sólo preferían "golosinas y frituras» y un $29.1 \%$ dijo que era por comer de todo pero en mucha cantidad (Encuesta propia 2017, Cuadro 10).

Sobre ¿Qué alimentos creen que más gusta a los niños? Las respuestas se reagruparon y codificaron en tres grupos: $54.2 \%$ creen que a los niños les gusta «solo dulces y golosinas»; $41.7 \%$ solo «dulces y frituras», mientras que para el $4.2 \%$ solo manifestaron las "frituras» haciendo hincapié en las hamburguesas (Encuesta propia 2017).

Con relación a los hábitos alimentarios en la crianza de los niños pequeños; la mitad (50\%) sostuvo que es normal que un nińo menor de 5 ańos coma tres veces al día; el $41.7 \%$ dijo "Cuatro veces por día»; mientras que el $4.2 \%$ creía que era mejor "Cinco veces al día» y otro grupo porcentaje $4.2 \%$ creía que era mejor «las veces que tenga hambre» (Encuesta propia 2017).

Explorando los estilos de vida de los pobladores y la práctica del deporte o la actividad física que acostumbran a realizar. El $37.5 \%$ declaró «Ninguno, o que no le gusta hacer deporte»; el 25\% dijo: «Correr en las mañanas»; «y hacer atletismo»; el 16.7\% declaró «jugar futbol». El 12.5\% integrado por mayores de 50 años, se mostraron mucho más pasivos, diciendo: «Ya no hago nada por la edad». Y solo el 8.3\% dijo que «no realiza ningún deporte por trabajar. No hay tiempo" (Encuesta propia 2017, Cuadro 11).

Los pobladores creen que la contextura de una persona es determinante en la salud; ser gorda o flaca tiene importancia para conservar la salud o para ser afectada por determinado tipo de enfermedades; en este sentido, consideraban que puede ser un factor de riesgo. Creen que los flacos son más propensos a sufrir de TBC, SIDA, enfermedades de transmisión sexual y de una gama de enfermedades infecciosas, aparentemente porque la capacidad inmunológica es más baja en los flacos. En oposición, creen que los gordos, son más propensos a sufrir de diabetes, enfermedades cardiovasculares, circulatorias, hepáticas $\mathrm{y}$ renales.

En torno a la relación entre el peso y la contextura de las personas con algunas enfermedades, se preguntó por el tipo de personas que podrían ser más afectadas por la tuberculosis, la mayoría, el $70.8 \%$ cree que son los «flacos»; sin embargo, para el 12.5\% puede ser «cualquier persona» incluso otro $12.5 \%$ señaló que eran las "personas normales»; y solo el 4.2\% dijeron creer que eran «los gordos» (Encuesta propia 2017).

La mayoría de los encuestados, $54 \%$ cree que «Cualquier persona» podía ser afectada por el SIDA; sin embargo, el $29.2 \%$ fue explícito en señalar que eran los flacos; el $16.7 \%$ señaló que eran los «normales» (Encuesta propia 2017).

En cuanto a las creencias acerca de la relación entre la contextura de las personas y las enfermedades, predominó que las personas gordas y muy gordas son las más afectadas por diversas enfermedades no transmisibles; el $70.8 \%$ cree que la diabetes es la principal enfermedad que los afecta (Encuesta propia 2017, Cuadro 27); sin embargo, el porcentaje más alto de los encuestados, $83.3 \%$ cree que son las enfermedades cardiovasculares que más los afecta (Encuesta propia 2017, Cuadro 28). Por otro lado, el 66.7\% de los encuestados cree que las enfermedades circulatorias también afectan a los más gordos. Con relación a las enfermedades hepáticas hay un $41.7 \%$ que cree que los gordos son los más afectados (Encuesta propia 2017); por último, el 50\% cree que las enfermedades renales afectan más a los gordos (Encuesta propia 2017).

Los encuestados también creen que hay enfermedades, como las mentales, de transmisión sexual y las cancerígenas que pueden afectar a todos por igual o a "cualquier persona»; la contextura tiene poca relación con tales enfermedades; sin embargo, hubo cierta variación en el número de respuestas: el $58.3 \%$ cree que las enfermedades mentales afectan a "cualquiera» (Encuesta propia 2017); también otro $58.3 \%$ cree que las enfer- 
medades de transmisión sexual afectan a "cualquiera» (Encuesta propia 2017); pero un grupo mayor, 66.7\% cree que son las enfermedades cancerígenas las que pueden afectar a «cualquiera» (Encuesta propia 2017).

El $87.5 \%$ cree que la misma obesidad es una enfermedad; aunque para el $12.5 \%$ no lo es (Encuesta propia 2017). Es interesante tener en cuenta las creencias en torno a las causas más importantes que determinan la obesidad. El 29.2\% cree que la causa principal está en "comer mucho por ansiedad y presión»; otro $29.2 \%$ cree que el factor está en la «mala alimentación; comer a destiempo y en grandes cantidades». El $20.8 \%$ cree que la causa está en «comer grasas, frituras y harinas; el 12.5 cree que la causa está en "no hacer ejercicios y llevar una vida sedentaria». Finalmente hay un 8.3 que encuentra como causa comer dulces» (Encuesta propia 2017).

Con relación a la forma cómo debe ser tratada o superada la obesidad, casi el 70\% de los encuestados, coincidieron en que el afectado debe «ir al médico y seguir el tratamiento", el $19.0 \%$ creía en una "dieta saludable, balanceada y con buena alimentación y/o practicar deporte»; el 12.0\% recomendaba ver al médico y a la nutricionista de la posta» (Encuesta propia 2017, Cuadro 12).
Con relación a la imagen del peso que tenían las personas. El $75.0 \%$ se consideraba normal; tenga exceso o déficit de peso (Encuesta propia: 2017, Cuadro $\mathrm{N}^{\circ} 40$ ); sin embargo, sólo el 58.3\% estaba satisfecho con su peso (Encuesta propia 2017).

En cuanto al momento en que las personas se dan cuenta que están con sobrepeso, el 33.3\% dijo «al sentir cansancio en las actividades»; otro 33.3\% manifestó al verse en el espejo y sentir la ropa apretada» (Encuesta propia 2017). Finalmente, cuando se les preguntó si estaban dispuestos a bajar de peso el 58\% no lo aceptaba; pero también el $83.3 \%$ no aceptaba subir de peso.

Durante la aplicación de las encuestas, muchos declaraban estar con un peso "normal» cuando era visible e innegable los kilos de exceso; sin embargo, en el proceso de la investigación lo normal, en la autopercepción de los pobladores, incluía el sobrepeso; incluso el déficit. Pero también, lo «normal» parecía estar dictado por la mayoría; ya que, si ésta tiene un evidente sobrepeso, entonces se puede definir como normal el peso de cada uno de los miembros de la comunidad.

En cuanto a los resultados de la observación, en total fueron observadas 2456 personas, de las cuales 375 , o el $15.27 \%$ aparentaban signos o señales de

Cuadro 1. Tiempos de observación y estimación de personas con obesidad y sobrepeso en espacios públicos de San Gabriel Alto

recreación Espacio comercial y de tránsito

\begin{tabular}{|c|c|c|c|c|c|c|c|c|c|}
\hline & \multicolumn{4}{|c|}{ Espacio de recreación } & \multicolumn{4}{c|}{ Espacio comercial y de tránsito } & Con \\
\hline $\begin{array}{c}\text { Personas } \\
\text { observadas }\end{array}$ & $\begin{array}{c}\text { Con } \\
\text { obesidad }\end{array}$ & $\begin{array}{c}\text { Con } \\
\text { sobrepeso }\end{array}$ & $\begin{array}{c}\text { Con peso } \\
\text { normal }\end{array}$ & Subtotal & $\begin{array}{c}\text { Con } \\
\text { obesidad }\end{array}$ & $\begin{array}{c}\text { Coso } \\
\text { sobrepeso }\end{array}$ & Subtotal & TOTAL \\
\hline Semana 1 y 2 & 34 & 143 & 86 & 263 & 65 & 187 & 106 & 358 & 621 \\
\hline Semana 3 y 4 & 43 & 118 & 90 & 251 & 66 & 277 & 191 & 534 & 785 \\
\hline Semana 5 y 6 & 84 & 187 & 162 & 433 & 83 & 298 & 236 & 617 & 1050 \\
\hline Total & 161 & 448 & 338 & 947 & 214 & 762 & 533 & 1509 & 100 \\
\hline
\end{tabular}

Fuente: Resultados del trabajo propio de observación

CuAdro 2. Número estimado de pobladores observados con obesidad y sobrepeso

\begin{tabular}{|c|c|c|c|c|c|c|c|c|}
\hline Espacios observados & \multicolumn{2}{|c|}{ Personas con obesidad } & \multicolumn{2}{|c|}{ Personas con sobrepeso } & \multicolumn{2}{|c|}{ Personas normales } & \multicolumn{2}{c|}{ Total } \\
\hline & $\mathrm{N}^{\circ}$ & $\%$ & $\mathrm{~N}^{\circ}$ & $\%$ & $\mathrm{~N}^{\circ}$ & $\%$ & $\mathrm{~N}^{\circ}$ & $\%$ \\
\hline Espacio de recreación & 161 & 6.56 & 448 & 18.24 & 338 & 13.76 & 947 & 38.56 \\
\hline Espacio de comercios & 214 & 8.71 & 762 & 31.03 & 533 & 21.70 & 1509 & 61.44 \\
\hline Total & 375 & 15.27 & 1210 & 49.27 & 871 & 35.46 & 2456 & 100.00 \\
\hline
\end{tabular}

FuENTE: Resultados del trabajo propio de observación 
exuberante gordura, que se interpretó como obesidad; por otro lado, 1210 personas, es decir casi la mitad, $49.27 \%$, presentaban señales de gordura y sobrepeso. Mientras que el $46 \%$ fueron observadas como normales, o personas delgadas. Estas estimaciones superan las proyecciones estadísticas oficiales, ya que éstas estiman porcentajes de personas gordas y muy gordas por debajo del $10 \%$ de la población distrital.

\section{Debate}

La Sociología de la Salud es la especialidad encargada de estudiar la nueva época, caracterizada por enfrentar el predominio de las enfermedades cardiovasculares, degenerativas, diabetes y las cancerígenas que afectan a millones de seres humanos de la sociedad global causado por un conjunto de factores, determinantes o fuerzas sociales, que incluyen la forma cómo trabajan, se alimentan, cómo descansan, "cómo viven, aman y mueren» (Camus 2003); destacando, en este proceso, los estilos de vida, la interacción, las identidades, las individualidades y sus manifestaciones como las situaciones de obesidad y sobrepeso. Éstos son factores que contribuyen a elevar los riesgos y probabilidades para la extensión de las enfermedades del siglo xxi. En el pasado, el estudio de las epidemias, de las enfermedades contagiosas y transmisibles, fue abordado por historiadores, médicos y científicos; no eran sociólogos pero durante el siglo XIX y parte del xx contribuyeron a abrir el camino a la Sociología y al estudio sociológico de la salud.

En este momento, nuestro país se encuentra en un proceso de transición, caracterizado por problemas que aún no han sido resueltos, como la desnutrición crónica y la anemia nutricional con otros, que crecen de manera diversa como es el caso de la obesidad, que aparecen en los comportamientos y en las mentalidades de pobladores locales como elementos derivados de las múltiples interacciones con los vientos de la modernidad y la globalidad. En estas condiciones el problema genera múltiples implicancias entre las autoridades, despistadas en unos casos y otros, en tratar el asunto de manera mecánica, paternalista, sin prestar atención a las particularidades culturales y ambientales de cada frente.

La obesidad y el sobrepeso es un problema de tipo energético donde el equilibrio se ha roto y convertido en un balance positivo y la ingesta de energía es mayor que la pérdida. El aporte de energía proviene de una sola fuente, los alimentos, mientras que la pérdida está dada por el metabolismo basal, la termogénesis y la actividad física. De todos estos componentes, los únicos que pueden ser sujetos a las variaciones de la voluntad son la ingesta y la actividad física.

La OMS relaciona la generación de algunas enfermedades, con el estilo de vida de las personas específicamente en lo que concierne a nuestra forma de alimentarnos. Manifestando que las características de algunos nutrientes se encuentran relacionadas a la aparición preocupante de las enfermedades emergentes como la obesidad, diabetes mellitus tipo 2, hipertensión arterial, dislipidemias y algunos cánceres.

En este marco es importante el abordaje sociológico para entender y comprender el actuar de las personas en el marco de la multiculturalidad y pluriculturalidad, por ello el estudio de las creencias y actitudes en la población es fundamental para que a través de actividades educativas permanentes, educación sanitaria para la vida se pueda contribuir desde diferentes escenarios con la mejora de estas creencias en bien de la salud, es decir acciones de promoción de la salud y prevención de enfermedades tal como lo establece desde 1980 la Declaración de Alma Ata, que solo abordando a las poblaciones más vulnerables con pobreza y extrema pobreza se podría reducir las enfermedades prevenibles antes mencionadas.

El estudio ha permitido encontrar brechas y diferencias culturales con relación a la buena nutrición y a la salud preventiva; que debe atenderse tanto en las actividades preventivas como en la promoción de la salud. En buena cuenta el estudio plantea como un reto a los trabajadores de la salud a prestar atención a las creencias, costumbres y actitudes de los pobladores para reorientar o hacer más efectivos sus programas preventivos y promocionales en nutrición y en el cuidado la salud.

Es necesario destacar que el avance de la tecnología ha hecho que en lo que se refiere a los alimentos se usen estrategias con la finalidad de darles una mejor 'presentación' para su consumo. Estos alimentos llamados procesados y ultraprocesados enmascaran cantidades no recomendables de azúcar, sodio, grasas saturadas y grasas trans que son consideradas dañinas para la salud y que han venido, entre otras cosas, a desplazar a los alimentos tradicionales no solo en 
las loncheras escolares sino en las mesas familiares, generando sobre peso y obesidad y dando origen a una serie de enfermedades prevenibles. Además, la publicidad crea su "gran paradoja» al postular cánones estéticos definidos por la delgadez, y al mismo tiempo ofertar continuamente la comida que se ha definido con toda razón como la gran fábrica de «gordos tristes». Los alimentos se obtienen hoy en el mercado donde son tratados como mercancías y no como nutrientes. Hoy no comemos lo que queremos sino lo que nos quieren vender, y no nos venden lo que alimenta sino lo que produce ganancias.

En cuanto a la obesidad y sobrepeso, en función de los resultados presentados se puede afirmar que en el Perú está presente con prevalencias preocupantes. El ámbito observado en las comunidades urbanas de San Gabriel Alto en Lima, es un escenario que condiciona en sus pobladores a prácticas, comportamientos y creencias en salud inadecuados, donde funcionan pollerías, salchipaperías, anticucherías, sandwicherías, bares y decenas de negocios informales; de expendio de gaseosas y golosinas; es decir de un mercado amplio y abierto que satisface la demanda y a la vez ejerce influencia y presión en el vecindario induciéndolo a consumir alimentos caracterizados como productos de malnutrición por los profesionales de la salud.

En cuanto a la estratificación social de la comunidad predomina la imagen de que los habitantes de los cerros de San Gabriel son pobres o pobres extremos; mientras que, para éstos al compararse con toda la población limeña, en efecto, expresaban una fuerte tendencia a subestimarse y a valorarse, en cuanto a posesión de status, por debajo de los habitantes especialmente de los barrios consolidados de la gran ciudad.

Es probable que el criterio que más influía al valorarse siempre como pobres o menos que todo el conjunto urbano, era el territorio que habitaban, por la exclusión de los servicios y por estar mapeados en las zonas con necesidades básicas insatisfechas; como contrapartida la imagen de los pobladores de los centros urbanos de los distritos de Lima Sur se ubicaba en los estratos medios y en los estratos altos a la gente de los distritos de San Isidro, Surco y la Molina. Este también es un aspecto importante en la valoración de la persona en el momento del consumo de alimentos, personas con baja autoestima, consumen más de lo necesario para su organismo como una forma de compensar sus necesidades afectiva, creándose un círculo vicioso al respecto.

En lo que se refiere a la contextura, si bien la mayoría se autodefinió como «normal», las observaciones precisaron que eran "chatos» con sobrepeso y con obesidad; y con predominio del género femenino; pero de éstos las dos terceras partes estaban con sobrepeso. En buena cuenta, se podría interpretar la historia nutricional de estas personas como un viaje de los extremos. De la desnutrición crónica infantil que experimentaron en las etapas de la invasión y ocupación de los terrenos por sus padres, pasaron a la obesidad y el sobrepeso en la vida madura y adulta, habitando ya una zona, que por el trabajo de la comunidad alcanzó un relativo desarrollo urbano. Lo que se ahonda con las creencias de este grupo que ser más gordo significa salud.

Existen porcentajes importantes como el 33\% de los pobladores que creen que la mayoría de los gordos son ricos; mientras que para el $41.7 \%$ la mayoría de los pobres son flacos. La evaluación de las creencias e imágenes que tienen los pobladores podría interpretarse como que la gordura es una señal de estatus, de mayor poder adquisitivo o simplemente de más poder.

Entre los factores que determinarían la gordura, según los pobladores se tiene que un porcentaje importante $41.7 \%$ cree que el más importante, es comer mucho; $20.8 \%$ piensan que los gordos «son los que no trabajan» o "hacen poco esfuerzo físico» (Encuesta propia), si es así es posible que algunos estén considerando que los gordos pertenecen a la "clase ociosa», a una clase parasitaria» o que descienden de los antiguos hacendados.

En las ideas de belleza, la mayoría (54\%) piensa que los niños más bonitos son normales y en menor porcentaje $(25 \%)$ opina que son los flacos. En este caso, la idea de lo normal es confusa; porque muchas señoras tenían bebes con sobrepeso y obviamente les parecía que éstos eran normales y bonitos.

Por consiguiente, el gordo, el obeso o la persona con sobrepeso no tienen una imagen repulsiva como podría tener en los sectores medios y en el campo de la farándula. Al contrario, en esta comunidad, es una buena señal para ser considerados por los demás como personas que comen bastante, que no sufren hambre; exponen la imagen de una supuesta o apa- 
rente riqueza. Por otro lado, esto se asocia al deseo de muchas madres de querer ver a sus hijos gorditos y tener la seguridad de estar alejadas de la desnutrición y la enfermedad, además, de no ser avergonzadas por una supuesta desatención a sus hijos, por la gente del barrio o por el personal de los establecimientos de salud.

En este sentido, es importante comprender las creencias y actitudes de los pobladores en situación de pobreza con relación a la malnutrición y a la salud, y la manera como las aborda la salud oficial y qué resultados se proponen lograr los promotores y trabajadores de la salud.

Está probado que el sobrepeso y la obesidad elevan las probabilidades de contraer enfermedades crónicas, degenerativas y cancerígenas, por esta razón hay un fuerte impulso desde diversos campos de la sociedad y el Estado por reducir estos problemas; pero en las comunidades urbanas donde se ejecutó el estudio hay una dinámica distinta, entre algunos grupos de pobladores en cuanto a las creencias y actitudes que favorecen, unidos a otros factores a la prevalencia de estos problemas y a una aparente sobrestimación de la gordura. El estudio logró identificar un conjunto de fuerzas que influyen en el comportamiento y en las creencias acerca del sobrepeso y la obesidad.

\section{Conclusiones}

El estudio de las epidemias y las enfermedades transmisibles y contagiosas en los contextos sociales de fines del siglo XIX fueron asumidos por médicos, o especialistas de las ciencias naturales, que terminaron finalmente haciendo sociología. En el siglo XXI el estudio de los determinantes, de las características, efectos e impactos de las epidemias y de las enfermedades crónicas, degenerativas y cancerígenas lo asume una sociología institucional, vinculada a los organismos multilaterales, al Estado y a la universidad, manteniendo siempre la preocupación por la vida y por las necesidades de planificación y desarrollo de los Estados.

Se ha expandido la mala nutrición por el excesivo consumo de grasas, dulces y harinas, tal como lo demuestran los últimos estudios científicos realizados por diversas instituciones. La presencia de polos contrarios que conviven en el estado nutricional de los pueblos y de las familias, podría explicarse como una etapa de transición alimentaria que acontece con el surgimiento del nuevo milenio, y que consiste en el paso de una alta prevalencia de desnutrición crónica a una etapa de baja desnutrición crónica y de creciente prevalencia de la obesidad y sobrepeso. Se trata de una transición con posibilidades de llegar a una etapa ideal definida por una prevalencia cero en desnutrición crónica y prevalencia cero en sobrepeso y obesidad.

Esta investigación se propuso conocer por qué los pobladores de una comunidad urbana como San Gabriel, teniendo información de los riesgos para la salud y de las mayores posibilidades de contraer enfermedades crónicas, cardiovasculares, degenerativas y cancerígenas, tienen actitudes favorables y de complacencia hacia la obesidad y el sobrepeso.

Una de las razones que explican las diferencias entre la información que disponen y las actitudes o comportamientos de los pobladores, tiene relación con el manejo de la imagen, con la representación y el significado en el mundo popular de la gordura o el sobrepeso. Muchos pobladores, incluso con educación secundaria, que se definen socialmente pertenecer a la clase media, asocian la gordura con la imagen de una persona de la ciudad y no del campo; si es menor, con la de un nińo limeño, y no de las provincias.

El ámbito observado en las comunidades urbanas de San Gabriel Alto en Lima, es un escenario que condiciona en sus pobladores a prácticas, comportamientos y creencias en salud inadecuados.

En este sentido, los padres especialmente las madres, que tienen hijos "gorditos" se sienten más seguros de ser aceptados y circular por la ciudad como personas normales, sin el temor de sufrir posibles discriminaciones. Con hijos gorditos y muy gordos sienten que tienen la llave para entrar a espacios que tradicionalmente los excluían, o que se sentían excluidos cuando ellos eran niños, por su delgadez y el dejo al hablar.

En cuanto a la estratificación social de la comunidad predomina la imagen de que los habitantes de los cerros de San Gabriel son pobres o pobres extremos.

En lo que se refiere a la contextura, si bien la mayoría se autodefinió como "normal», las observaciones precisaron que eran "chatos» con sobrepeso y con obesidad; y con predominio del género femeni- 
no; pero de éstos las dos terceras partes estaban con sobrepeso

Existen porcentajes importantes como el 33\% de los pobladores que creen que la mayoría de los gordos son ricos; mientras que para el $41.7 \%$ la mayoría de los pobres son flacos.

Entre los factores que determinan la gordura, según los pobladores se tiene que un porcentaje importante cree que el más importante, es comer mucho; y en menor número piensan que los gordos «son los que no trabajan» o "hacen poco esfuerzo físico»

La gordura como una señal de status se refuerza en los espacios públicos, por las atenciones que reciben de los comerciantes y por las miradas que provocan de otras personas hacia los que destacan por su gordura, vestimenta y comportamiento a veces un tanto exhibicionista. Además, del mercado que presiona y condiciona en la formación de los hábitos alimentarios está el discurso sobre los productos industriales, vistos como «urbanos», «de mejor calidad" y sobre todo que dan prestigio a quien lo consume.

En las ideas de belleza, la mayoría (54\%) piensa que los niños más bonitos son normales y en menor porcentaje (25\%) opina que son los flacos.

Para los jóvenes, es importante un cuerpo delgado, alto y adornado de acuerdo a la moda; pero para los hijos pequeños o para los hermanos menores prefieren un cuerpo robusto. Ellos se sienten más satisfechos en el vecindario al tener un familiar "gordito" que uno que parezca enfermo por su delgadez.

En el mundo contemporáneo de los últimos 20 años, la obesidad y el sobrepeso se han convertido en un mal epidémico de alto riesgo para la vida de las personas y de los pueblos porque eleva las probabilidades de conectarse a una gama de enfermedades crónicas, cancerígenas, degenerativas, cardiovasculares incluso mentales. Se ha transformado en una creciente pandemia que abarca al mundo globalizado, a los habitantes de grandes y pequeñas ciudades; a las clases altas, pero también a las poblaciones en situación de pobreza, pobreza extrema y exclusión social. En suma, a todas las familias conectadas a los estilos de vida concordantes con la cultura moderna, con gustos sujetos al mercado, a las variantes y remedos de los «fast food».

En el mundo popular tienen conocimiento de la relación entre las situaciones de obesidad y sobrepeso con las enfermedades cardiovasculares, degenerativas, diabetes y cancerígenas; pero los padres de familia de diversos estratos sociales de la zona creen que esas enfermedades afectan solo a las personas mayores y creen que sus hijos tienen tiempo para bajar de peso, si ellos ya como personas mayores así lo quisieran.

\section{Recomendaciones}

Continuar explorando las creencias y actitudes de los sectores populares como pautas culturales frente a la obesidad y el sobrepeso con la finalidad de aportar a la reorientación de las políticas y programas de salud, educación y cultura; a mejorar los programas preventivo-promocionales; reorientar los programas de información y capacitación en salud y nutrición en los asentamientos humanos, en las comunidades rurales y urbanas

Promover la investigación multidisciplinaria en la Universidad a fin de estudiar los problemas de salud y nutrición asociados a la cultura y a las fuerzas sociales en cada contexto regional y local.

Promover la coordinación multisectorial entre Ministerio de Salud, Educación, Municipalidad, Universidad y las organizaciones populares para establecer políticas y estrategias de promoción de estilos de vida saludables en las poblaciones.

Que las instituciones de salud impulsen de manera frontal el desarrollo de actividades educativas sanitarias masivas a fin de sensibilizar a la población en su auto responsabilidad frente a su cuidado y el de los menores. 


\section{Bibliografía}

Briseño, R. (2008). Endemias, epidemias y modas: la sociología de la salud en América Latina. pp. 69-85. Recuperado de: http://www.fes-sociologia.com/files/ res/3/04.pdf

Camus, A. (2003). La peste. Lima: El Comercio. Colección Premios Nóbel

CEPAL (2016). Agenda 2030 y los objetivos de desarrollo sostenible. Chile: CEPAL. Recuperado de: http://www. sela.org/media/2262361/agenda-2030-y-los-objetivosde-desarrollo-sostenible.pdf

Dirección de Salud II Lima Sur DISA II (2014). La situación de salud de Lima Sur. Recuperado de: http://bvs. minsa.gob.pe/local/MINSA/3358.pdf

Elías, N. (2011). El proceso de la civilización. México: FCE.

Galvao, L.A., Finkelman, J., Senao, J (2010). Determinantes ambientales y sociales de la salud. Washington: Organización Panamericana de la Salud.

García, Juan César (2007). Clásicos en Medicina Social. Entrevista en Medicina Social 2 (3) 2007 pp.7 Recuperado de: http://www.socialmedicine.info/index. $\mathrm{php} / \mathrm{medicinasocial/article/view/132/269}$

García, J. C. (1963). Sociología y medicina: bases sociológicas de las relaciones médico-paciente. Cuadernos Médico Sociales, 4:11-16. - 1989.

Hernández H. (2010). Modelo de creencias de salud y obesidad. Un estudio de los adolescentes de la provincia de Guadalajara. Tesis doctoral. Alcalá de Henares. Recuperado de: http://dspace.uah.es/dspace/bitstream/ handle/10017/9024/TESIS\%20

INEI (2017). Resultados de la encuesta demográfica y de salud familiar ENDES. Lima. Recuperado 202016\%20PresentacPPT.pdfde:file:///D:/Aa\%20 COCO\%202018/SOCIOLOGIA\%20DE\%20 LA\%20SALUD\%202018/ENDES\%

INEI (20 junio 2016). Nota de Prensa. El 35,5\% de la población peruana de 15 y más años de edad padece de sobrepeso. Lima: INEI Recuperado de: ww.inei.gob.pe/ prensa/noticias/el-355-de-la-poblacion-peruana-de15-y-mas-anos-de-edad-padece-de-sobrepeso-9161/

INEI (2014). POBLACION. Recuperado de: http://search. searchdconvertnow.com/?uc=20170219\&ap=appfocu s5\& source= googledisplay\&uid=5513c26f-e69e-466375 d7d92ed7c25d3\&i_id=converter_6.1\& \&id=mlbegl eoeglcjckomgocdhcmhcgnjffp\&page $=$ newtab\&

Matos, J. (2013). PERÚ Estado desbordado y sociedad nacional emergente. Lima: URP.

Meneses, M. (2010). El impacto social de los proyectos de agua y alcantarillado en los sectores populares de Lima Metropolitana. En: PAIDEIA XXI. Revista de la Escuela de Posgrado. Lima: Universidad Ricardo Palma. 1 (1) pp. 77-90.

Meneses, M. (2010). Población, migración y urbanización en el Perú 1940-2010. En: Julio Mejía, editor, Realidad nacional, sociedad, Estado y cultura en el Perú contemporáneo. Lima: Editorial Universitaria. Universidad Ricardo Palma, pp. 61-97.

MINSA (2013). Análisis de la situación de salud del Perú. Lima: MINSA. Dirección General de Epidemiología. Recuperado de: http://www.dge.gob.pe/portal/docs/ intsan/asis2012.pdf

Organización Mundial de la Salud (2018). Temas de salud. Recuperado de: http://www.who.int/es/; http:// www.who.int/topics/obesity/es/

Organización Mundial de la Salud (2010). Estadísticas sanitarias 2010. Recuperado en: http://www.who. int/gho/publications/world_health_statistics/ES_ WHS10_Full.pdf?ua=1

ONU (2015). Objetivos del desarrollo del milenio. Informe del 2015. Recuperado de: http://www.un.org/es/millenniumgoals/pdf/2015/mdg-report-2015_spanish. pdf

Sifuentes, E. (2012). Perú 1950-2010: Crecimiento económico y desnutrición crónica desde el desarrollo regional. Revista del Instituto de Investigaciones Históricosociales $\mathrm{N}^{\circ} 28$, pp. 59-79. Lima. Facultad de Ciencias Sociales.UNMSM

Sifuentes, E. (2012). Energía social y teoría sociológica. Revista de Sociología N²2, pp. 313-328. Lima: UNMSM.

Sifuentes, E. (2014). Orina y excremento entre sociedades, remedios y salud pública. Revista de Sociología 22. pp. 231-253. Lima: Escuela de Sociología UNMSM.

ZÁrate, E. (2014). La mayor epidemia del siglo XIX. Lima 1868 fiebre amarilla. Lima: Novo Dezain. 


\section{ANEXOS}

1. Nińos y madres de familia residentes de San Gabriel Alto IV y V Etapas
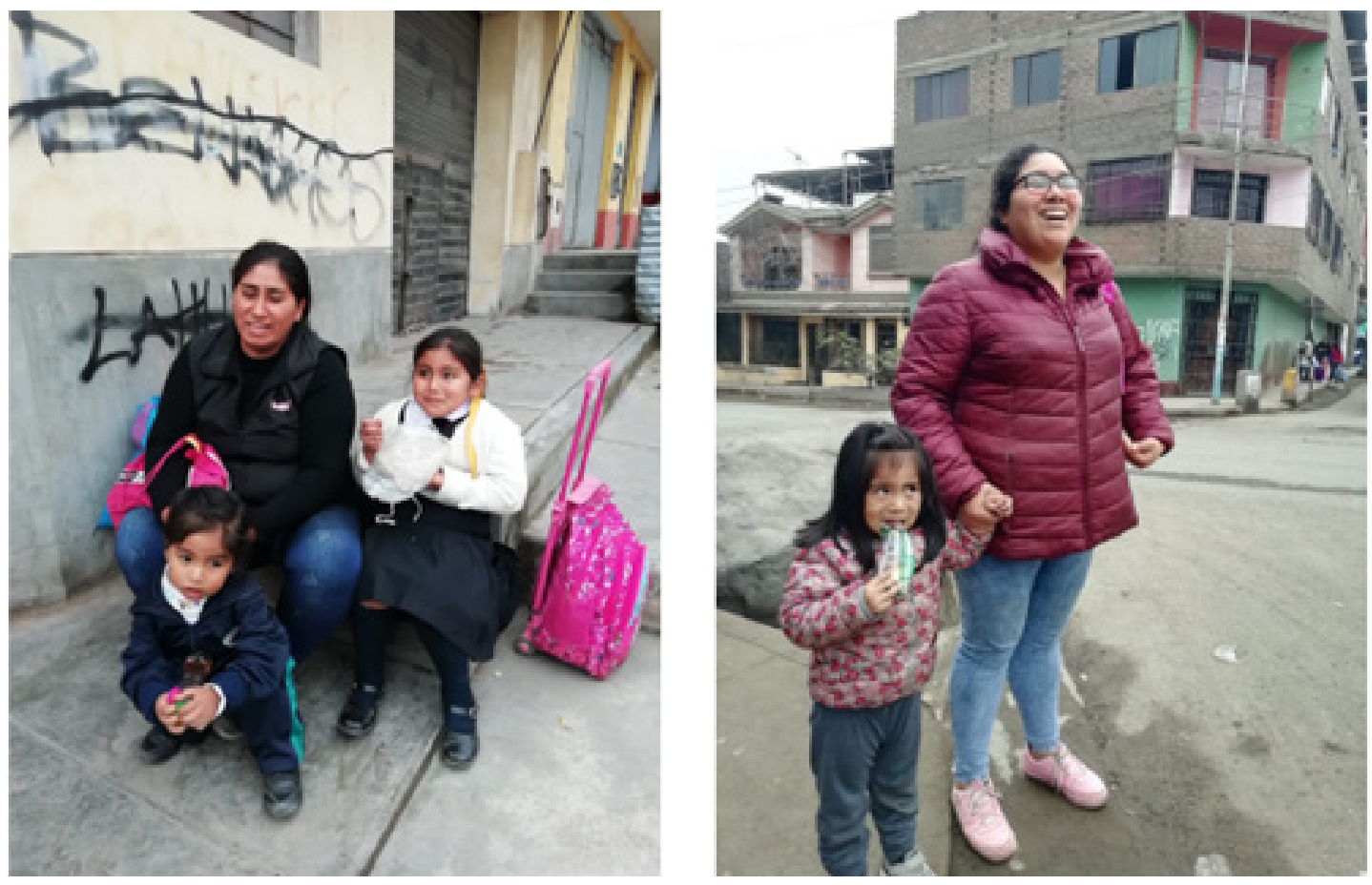

Madres con sobrepeso y niñas con exceso o déficit de peso. San Gabriel Alto VMT, Lima (FOTOS: Eudosio Sifuentes)
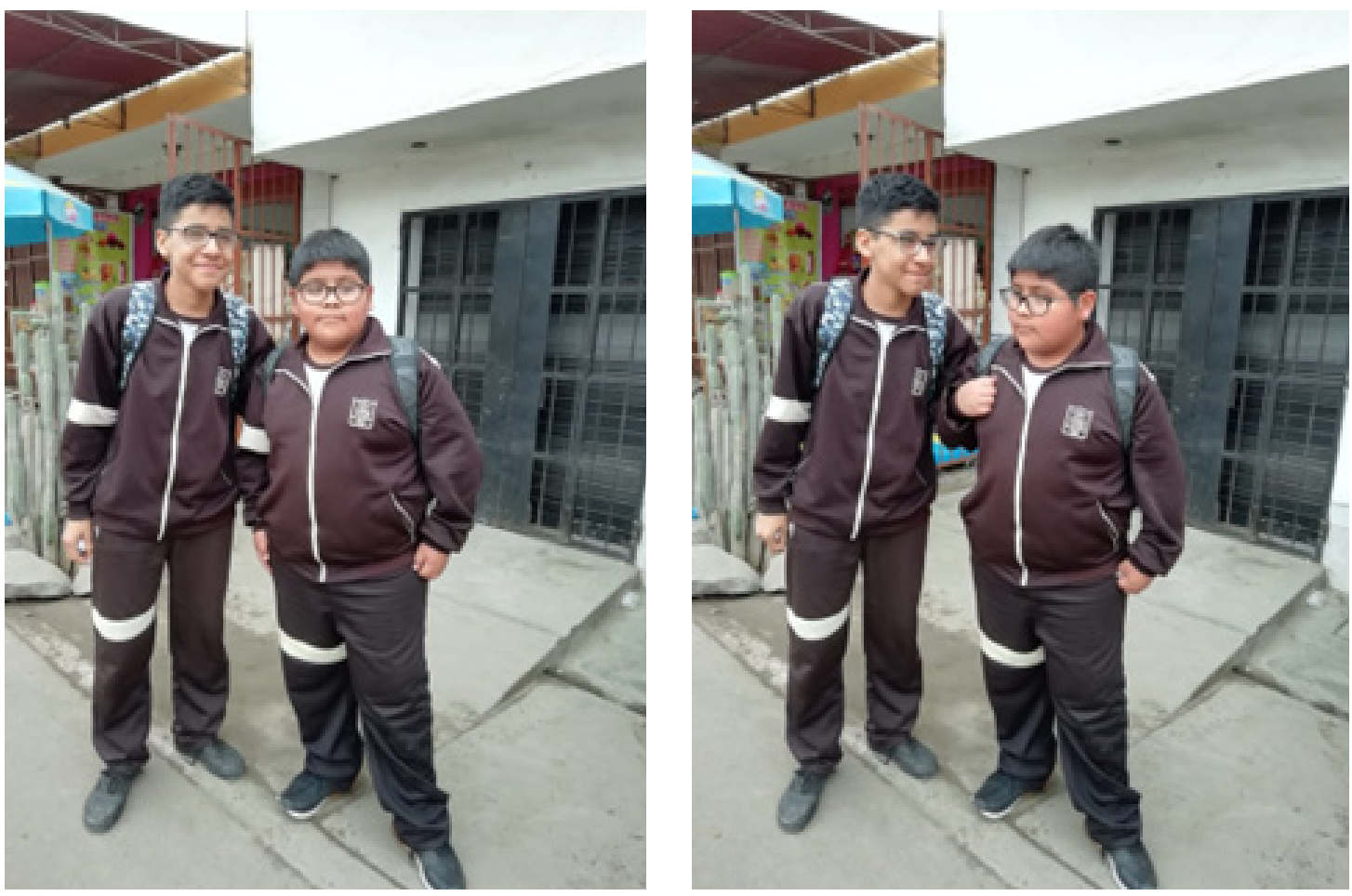

Creciente prevalencia de la obesidad y sobrepeso en la población infantil de San Gabriel Alto (FOTOS: Eudosio Sifuentes) 

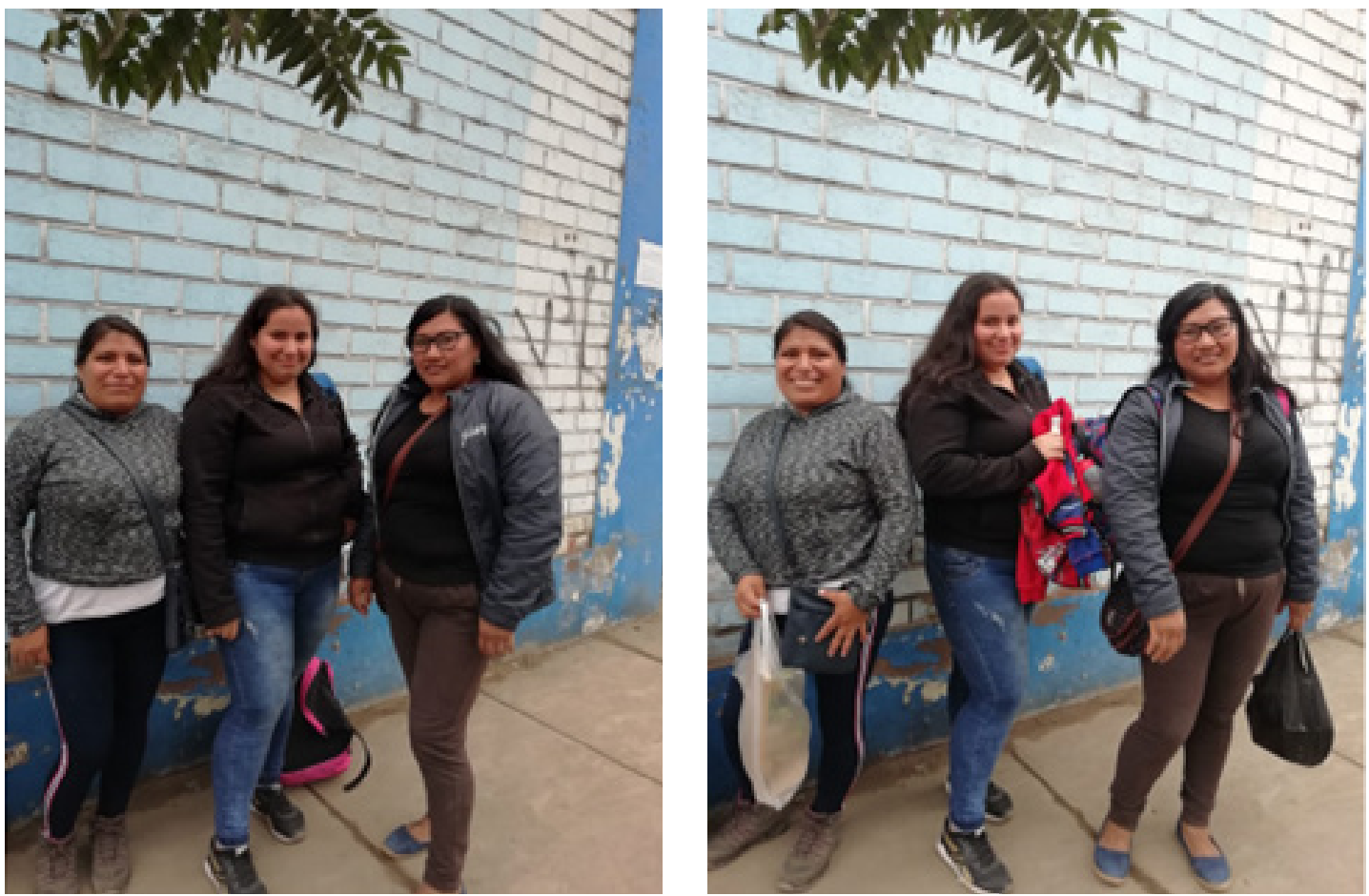

Madres de familia con sobrepeso y obesidad, pero felices en San Gabriel Alto (FOTOS: Eudosio Sifuentes)
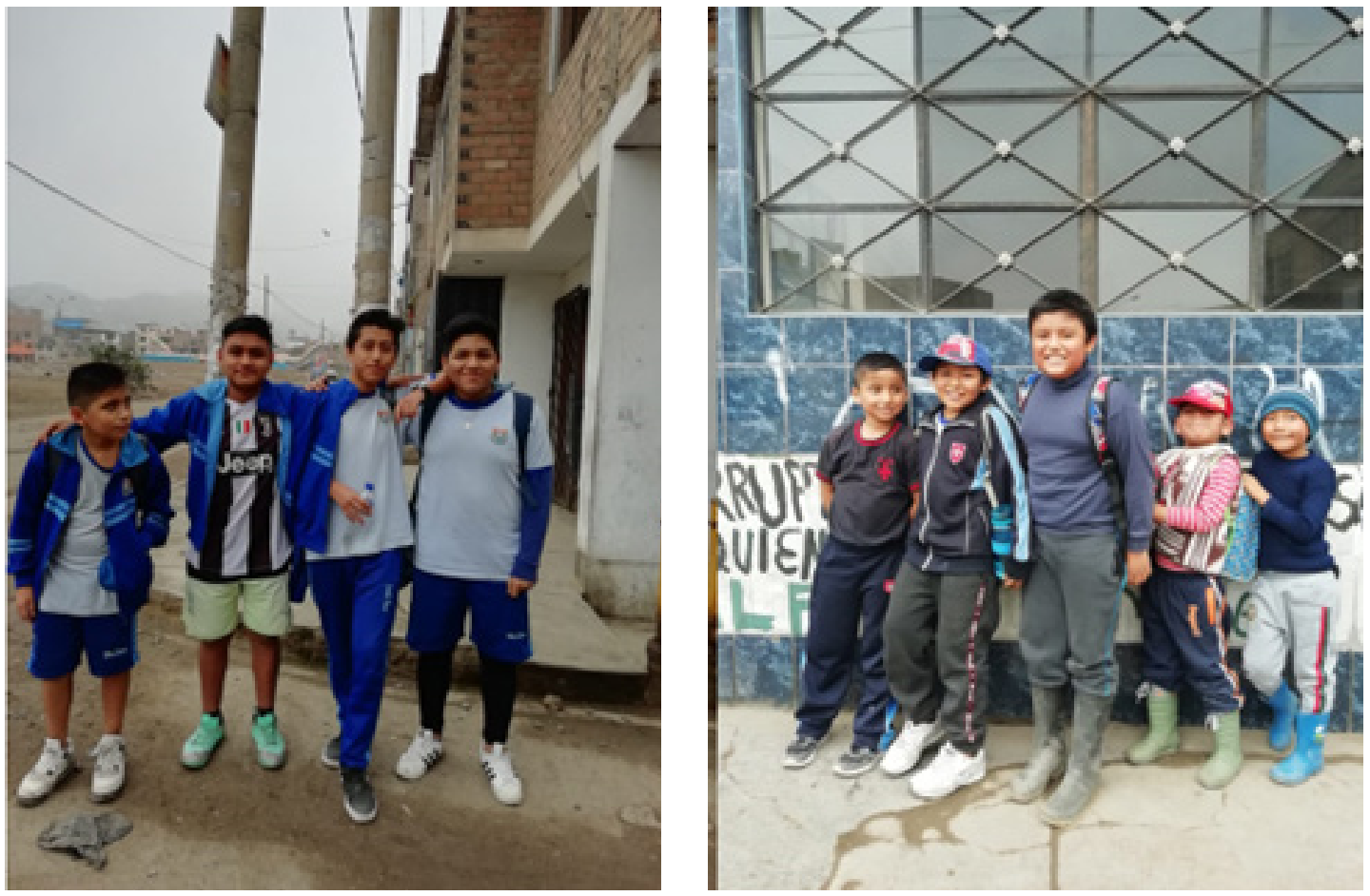

Entre los niños de cada grupo hay diferencias de edad de solo 6 meses. Evidencian desnutrición y sobrepeso. La mayoría de ellos tienen madres obesas (FOTOS: Eudosio Sifuentes) 
2. ENCUESTA PROPIA. Algunos resultados de la encuesta aplicada a 240 personas, madres o padres de familia, de San Gabriel Alto IV y V Etapa. Distrito de Villa María del Triunfo. Lima Sur.

CUADro 3. CARACTERÍSTICAS GENERALES DE LA POBLACION DE ESTUDIO

\begin{tabular}{|l|c|}
\hline Datos generales & Frecuencia $\%$ \\
\hline Procedencia & \\
\hline Personas que nacieron en Lima & $58.4 \%$ \\
\hline $\begin{array}{l}\text { Tiene raíces en comunidades } \\
\text { rurales o de provincia }\end{array}$ & $65.7 \%$ \\
\hline Educación & Frecuencia $\%$ \\
\hline Primaria & $20.8 \%$ \\
\hline Secundaria & $41.7 \%$ \\
\hline Superior & $37.5 \%$ \\
\hline TOTAL & $100.0 \%$ \\
\hline Talla & Frecuencia $\%$ \\
\hline $1.50 \mathrm{~m}$ & $4.6 \%$ \\
\hline Entre 1.51 y $1.60 \mathrm{~m}$ & $64.2 \%$ \\
\hline 1.61 a $1.70 \mathrm{~m}$ & $31.2 \%$ \\
\hline TOTAL & $100.0 \%$ \\
\hline & \\
\hline Peso & Frecuencia $\%$ \\
\hline $51-60$ kg & $33.3 \%$ \\
\hline 61 y $70 \mathrm{~kg}$ & $41.7 \%$ \\
\hline No sabían su peso & $25.0 \%$ \\
\hline TOTAL & $100.0 \%$ \\
\hline Índice de masa corporal (IMC) & \\
\hline $25-30$ (sobrepeso) & Frecuencia $\%$ \\
\hline Más de 30 (obeso) & $47.5 \%$ \\
\hline Menos de 25 & $8.3 \%$ \\
\hline TOTAL & \\
\hline Chatos y gruesos, obesos & \\
\hline Aparentemente normal & \\
\hline TOTAL & \\
\hline
\end{tabular}

CUAdro 4. PERCEPCIONES SOBRE LA BELLEZA FÍSICA

\begin{tabular}{|l|c|}
\hline Percepciones sobre la belleza física & Frecuencia \% \\
\hline $\begin{array}{l}\text { Las personas bonitas tienen una } \\
\text { «contextura normal» }\end{array}$ & $58.3 \%$ \\
\hline $\begin{array}{l}\text { Las personas bonitas tienen } \\
\text { cualquier contextura }\end{array}$ & $16.7 \%$ \\
\hline Las personas bonitas son gordas & $8.3 \%$ \\
\hline Las personas bonitas son flacas & $16.7 \%$ \\
\hline TOTAL & $100.0 \%$ \\
\hline
\end{tabular}

CUADro 5. ¿QUIÉNES SON MÁS FELICES?

\begin{tabular}{|l|c|}
\hline ¿Quiénes son más felices? & Frecuencia $\%$ \\
\hline El nińo de peso «normal» & $33.3 \%$ \\
\hline Cualquier persona gorda o flaca & $37.5 \%$ \\
\hline Cuando se es «gordito» & $29.2 \%$ \\
\hline TOTAL & $100.0 \%$ \\
\hline
\end{tabular}

CuAdro 6. SITUACIÓN ECONÓMICA, CLASE SOCIAL Y CONTEXTURA

\begin{tabular}{|l|c|}
\hline Situación económica y contextura & Frecuencia $\%$ \\
\hline Los ricos son gordos & $33.3 \%$ \\
\hline Los ricos son «normales en peso» & $25.0 \%$ \\
\hline Los ricos son gordos o flacos & $25.0 \%$ \\
\hline Los ricos son flacos & $16.7 \%$ \\
\hline TOTAL & $100.0 \%$ \\
\hline & \\
\hline Clase social y contextura & Frecuencia $\%$ \\
\hline Los pobres son flacos & $41.7 \%$ \\
\hline El pobre tiene contextura normal & $29.2 \%$ \\
\hline $\begin{array}{l}\text { El pobre puede ser flaco o tener } \\
\text { contextura normal }\end{array}$ & $25.0 \%$ \\
\hline Los pobres son gordos & $4.2 \%$ \\
\hline TOTAL & $100.0 \%$ \\
\hline
\end{tabular}


CUAdro 7. CONTEXTURA Y ENFERMEDAD

\begin{tabular}{|l|c|}
\hline Contextura y enfermedad & Frecuencia \% \\
\hline $\begin{array}{l}\text { El enfermo puede tener cualquier } \\
\text { contextura }\end{array}$ & $62.5 \%$ \\
\hline Los gordos son más propensos a enfermar & $20.8 \%$ \\
\hline Los flacos son más propensos a enfermar & $16.7 \%$ \\
\hline TOTAL & $100.0 \%$ \\
\hline
\end{tabular}

\section{CUADro 9. FACTORES QUE INFLUYEN EN LA} GORDURA

\begin{tabular}{|l|c|}
\hline Factores que influyen en la gordura & Frecuencia $\%$ \\
\hline $\begin{array}{l}\text { Mala alimentación: comida chatarra, } \\
\text { grasas, frituras }\end{array}$ & $51.7 \%$ \\
\hline Falta de ejercicios y mala alimentación & $21.8 \%$ \\
\hline Tener vida sedentaria, no trabajar & $13.5 \%$ \\
\hline $\begin{array}{l}\text { Haber tenido enfermedades y falta de } \\
\text { higiene }\end{array}$ & $13.0 \%$ \\
\hline TOTAL & $100.0 \%$ \\
\hline
\end{tabular}

\section{CuAdro 11. ESTILOS DE VIDA RESPECTO AL EJERCICIO DE LOS POBLADORES}

\begin{tabular}{|l|c|}
\hline Ejercicios & Frecuencia \% \\
\hline No hace ningún deporte porque no desea & $37.5 \%$ \\
\hline Correr en las mañanas o hacer atletismo & $25.0 \%$ \\
\hline Jugar fútbol & $16.7 \%$ \\
\hline $\begin{array}{l}\text { No hace nada por la edad (mayores de } 50 \\
\text { años) }\end{array}$ & $12.5 \%$ \\
\hline No tiene tiempo por trabajar & $8.3 \%$ \\
\hline TOTAL & $100.0 \%$ \\
\hline
\end{tabular}

\section{CUADro 8. AUTOIMAGEN DE LOS POBLADORES Y SATISFACCIÓN QUE LES GENERA}

\begin{tabular}{|l|c|}
\hline Autoimagen de los pobladores & Frecuencia \% \\
\hline $\begin{array}{l}\text { Se ven «normales» pero se les observó } \\
\text { gordos o con sobrepeso }\end{array}$ & $83.3 \%$ \\
\hline Se considera «gordo» & $12.5 \%$ \\
\hline $\begin{array}{l}\text { Se considera «flaco» aun observándose en } \\
\text { contextura normal o sobrepeso }\end{array}$ & $4.2 \%$ \\
\hline TOTAL & $100.0 \%$ \\
\hline
\end{tabular}

\begin{tabular}{|l|c|}
\hline Satisfacción que les genera & Frecuencia \% \\
\hline $\begin{array}{l}\text { Se siente contento con su contextura } \\
\text { (sobrepeso o déficit) }\end{array}$ & $83.0 \%$ \\
\hline Está descontento con su contextura & $12.5 \%$ \\
\hline En duda, no sabe & $4.5 \%$ \\
\hline TOTAL & $100.0 \%$ \\
\hline
\end{tabular}

\section{CuAdro 10. CREENCIAS SOBRE LOS FACTORES QUE ELEVAN EL PESO Y LA GORDURA}

\begin{tabular}{|l|c|}
\hline $\begin{array}{l}\text { Creencias sobre los factores que elevan el } \\
\text { peso y la gordura }\end{array}$ & Frecuencia \% \\
\hline $\begin{array}{l}\text { Comer Solo frituras, comida chatarra, } \\
\text { grasas, comida grasosa }\end{array}$ & $41.7 \%$ \\
\hline $\begin{array}{l}\text { Comer dulces, golosinas, harinas, pastas, } \\
\text { frituras y comidas grasosas }\end{array}$ & $16.7 \%$ \\
\hline Comer muchas golosinas y frituras & $12.5 \%$ \\
\hline Comer de todo y mucho & $29.1 \%$ \\
\hline TOTAL & $100.0 \%$ \\
\hline
\end{tabular}

CuAdro 12. COMO DEBE SER TRATADA LA OBESIDAD

\begin{tabular}{|l|c|}
\hline Como debe ser tratada la obesidad & Frecuencia \% \\
\hline Debe ir al médico y seguir tratamiento & $70.0 \%$ \\
\hline $\begin{array}{l}\text { Seguir una dieta saludable o practicar } \\
\text { deportes }\end{array}$ & $19.0 \%$ \\
\hline Ir al médico y nutricionista & $12.0 \%$ \\
\hline TOTAL & $100.0 \%$ \\
\hline
\end{tabular}

